\title{
Chronic Tic Disorder
}

National Cancer Institute

\section{Source}

National Cancer Institute. Chronic Tic Disorder. NCI Thesaurus. Code C116768.

A neurological disorder presenting in childhood that is characterized by either motor or phonic tics, but not both, that occur daily or nearly daily for at least a year and are not attributed to an identifiable cause. 